\title{
COOPERACIÓN REFORZADA \\ EN EL RECONOCIMIENTO, EJECUCIÓN \\ Y APLICACIÓN DE LAS DECISIONES EN EL MARCO \\ DE LOS REGLAMENTOS GEMELOS ${ }^{1 *}$
}

\author{
JerCa KraMberger ŠKerL \\ Profesora Titular y Vicedecana de Asuntos Económicos e investigación \\ de la Facultad de Derecho de la Universidad de Liubliana \\ E-mail: jerca.kramberger@pf.uni-lj.si
}

\begin{abstract}
RESUMEN: Se analizan los diferentes aspectos del reconocimiento y la ejecución de las resoluciones, siendo preciso aportar en esta introducción información básica sobre la aplicabilidad de los Reglamentos gemelos, como las definiciones del término "resolución" y de la autoridad que debía dictarla, atendiendo al ámbito de aplicación territorial, temporal y material.

Palabras clave: Órgano jurisdiccional, exequatur, reconocimiento y ejecución de resoluciones, régimen económico matrimonial, efectos patrimoniales de las uniones registradas.

ABSTRACT: The different aspects of the recognition and enforcement of decisions are analysed. The article first provides basic information on the applicability of the Twin Regulations, such as the definitions of the term "decision" and the authority that was to issue it, as well as on the territorial, temporal and material scope of application. Then, the article deals with the recognition and the declaration of enforceability of decisions under the Twin Regulations.
\end{abstract}

Keywords: Court, exequatur, recognition and enforcement of decisions, matrimonial property regimes, property consequences of registered partnerships.

SUMARIO: I. INTRODUCCIóN. 1.1. ¿Qué decisiones pueden circular según las normas de los reglamentos gemelos?. 1.2. Órganos jurisdiccionales. 1.3. Ámbito de aplicación territorial y temporal. 1.4. Ámbito de aplicación material. II. RECONOCIMIENTo. III. La DECLARACIón DE EJECUTORIEDAD (EXEQUatur). 3.1. La admisibilidad de la solicitud de exequatur. 3.2. Procedimientos en primera instancia. 3.3. Recurso(s) contra el otorgamiento de la ejecución. 3.4. Medidas provisionales o cautelares, antes y durante el procedimiento de exequatur. 3.5. Costes del procedimiento de exequatur. IV. Motivos de DeNEGACión De REConocimiento Y EJECUCión. 4.1. La excepción de orden público. 4.2. La falta de notificación del documento introductorio en el procedimiento. 4.3. Motivos de denegación del reconocimiento de las resoluciones. 4.4. Orientaciones adicionales sobre el examen de motivos de denegación. V. OBSERVACIONES FINALES.

$1{ }^{*}$ Traducido por Ana María Pérez Vallejo, Profesora Titular de Derecho civil y Nuria Martínez Sánchez, Doctora en el departamento de Derecho civil de la Universidad de Almería. 


\section{INTRODUCCIÓN}

La primera mención del plan de la UE para permitir la libre circulación de decisiones dentro de sus fronteras se encuentra en las conclusiones del Consejo Europeo de Tampere de octubre de 1999, ${ }^{2}$ que respaldó el principio de reconocimiento mutuo de las sentencias y otras decisiones de las autoridades judiciales como piedra angular de la cooperación judicial en asuntos civiles e invitó al Consejo y a la Comisión a adoptar un programa de medidas para aplicar dicho principio. En el proyecto de programa de medidas de $2001,{ }^{3} \mathrm{se}$ pide que se actúe específicamente en los ámbitos del Derecho de familia no cubiertos por los instrumentos entonces existentes. La necesidad de avanzar en este ámbito se reiteró en el Programa de La Haya ${ }^{4}$ y se concretó aún más en el Programa de Estocolmo, adoptado en una reunión del Consejo Europeo en diciembre de 2009. ${ }^{5}$ Este último especificó que las futuras normas debían respetar "los sistemas jurídicos de los Estados miembros, incluido el orden público (order public), y las tradiciones nacionales en este ámbito".

Estos planes y programas fueron seguidos por la acción legislativa y se adoptaron varios Reglamentos que ampliaron considerablemente la unificación en la UE de las normas sobre reconocimiento y ejecución de decisiones en el ámbito del Derecho de familia. Mientras que el Reglamento Bruselas II bis, ${ }^{6}$ el Reglamento sobre obligación de alimentos $^{7}$ y el Reglamento sobre sucesiones ${ }^{8}$ son aplicables en el territorio de toda la UE, el más reciente Reglamento sobre regímenes económicos matrimoniales ${ }^{9}$ y el Reglamento sobre los efectos patrimoniales de las uniones registradas ${ }^{10}$ (en lo sucesivo, ambos Reglamentos se denominarán conjuntamente los Reglamentos gemelos) son actualmente aplicables en la mayoría de los Estados miembros de la UE, pero no en todos. Al igual que el anterior Reglamento Roma III (que, sin embargo, no aborda el reconocimiento y la ejecución de las decisiones), ${ }^{11}$ los Reglamentos gemelos se adoptaron concretamente en el marco del sistema de cooperación reforzada, ${ }^{12}$ ante la falta de un posible consenso "en un plazo razonable

2 Tampere European Council 15 and 16 October 1999 Presidency Conclusions, < https://www.europarl.europa.eu/ summits/tam en.htm\#c>, accessed 06.07.2021.

3 Draft programme of measures for implementation of the principle of mutual recognition of decisions in civil and commercial matters [2001] OJ C12.

4 The Hague Programme: Strengthening Freedom, Security and Justice in The European Union [2005] OJ C53.

5 The Stockholm Programme - An open and secure Europe serving and protecting citizens [2010], OJ C115.

6 Council Regulation (EC) no 2003/2201 of 27 November 2003 concerning jurisdiction and the recognition and enforcement of judgments in matrimonial matters and the matters of parental responsibility, repealing Regulation (EC) no 2000/1347 [2003] OJ L338.

7 Council Regulation (EC) No 4/2009 of 18 December 2008 on jurisdiction, applicable law, recognition and enforcement of decisions and cooperation in matters relating to maintenance obligations [2009] OJ L7.

8 Regulation (EU) No 650/2012 of the European Parliament and of the Council of 4 July 2012 on jurisdiction, applicable law, recognition and enforcement of decisions and acceptance and enforcement of authentic instruments in matters of succession and on the creation of a European Certificate of Succession [2012] OJ L201.

9 Council Regulation (EU) 2016/1103 of 24 June 2016 implementing enhanced cooperation in the area of jurisdiction, applicable law and the recognition and enforcement of decisions in matters of matrimonial property regimes [2016], OJ L183/1.

10 Council Regulation (EU) 2016/1104 of 24 June 2016 implementing enhanced cooperation in the area of jurisdiction, applicable law and the recognition and enforcement of decisions in matters of the property consequences of registered partnerships [2016] OJ L183/1.

11 Council Regulation (EU) No 1259/2010 of 20 December 2010 implementing enhanced cooperation in the area of the law applicable to divorce and legal separation [2010] OJ L343.

12 La posibilidad de adoptar un reglamento en el marco de la cooperación reforzada está prevista en el artículo 326 y en los siguientes artículos de la versión consolidada del Tratado de Funcionamiento de la UE [2012] DO C326. 
por parte de la Unión en su conjunto". ${ }^{13}$ Dieciocho Estados miembros se adhirieron a la cooperación reforzada en relación con estos Reglamentos. ${ }^{14}$

Antes de entrar en el análisis de los diferentes aspectos del reconocimiento y la ejecución de las resoluciones, es preciso aportar en esta introducción información básica sobre la aplicabilidad de los Reglamentos gemelos, como las definiciones del término "resolución" y de la autoridad que debía dictarla, así como los contornos del ámbito de aplicación territorial, temporal y material.

\section{1. ¿Qué decisiones pueden circular según las normas de los reglamentos gemelos?}

Ambos Reglamentos utilizan el término "decisiones", como el Reglamento de sucesiones, y no "sentencias", como el Reglamento de Bruselas I bis. ${ }^{15}$ Esto puede ser útil para determinar qué actos pueden circular con arreglo a las normas de los Reglamentos gemelos. Mientras que el término "sentencia" implica que la autoridad emisora es el tribunal, el término "resolución" parece más abierto en cuanto al organismo emisor, que puede ser también un notario u otra autoridad o profesión investida de poderes judiciales en el ámbito material de aplicación del Reglamento. ${ }^{16}$ Teniendo esto en cuenta, los términos “decisión” y "juicio” se utilizarán indistintamente en este capítulo.

El artículo 3, apartado 1, letra d), del Reglamento UE nº 2016/1103 establece que "resolución" significa cualquier decisión en materia de régimen económico matrimonial dictada por un tribunal de un Estado miembro, cualquiera que sea su denominación, incluida la decisión sobre la determinación de las costas o los gastos por parte de un funcionario del tribunal. La letra e) del apartado 1 del artículo 3 del Reglamento UE $n^{\circ}$ 2016/1104 sobre los efectos patrimoniales de las uniones registradas contiene una disposición idéntica, naturalmente con la referencia a las cuestiones de las consecuencias patrimoniales de una unión registrada.

Aunque está claro que las decisiones sobre el fondo del litigio son admisibles, podría ser importante destacar que las medidas provisionales y cautelares no están exentas. Así lo aclaró el Tribunal de Justicia de la UE (en adelante, el TJUE) en la sentencia Denilauler, relativa al Convenio de Bruselas, en la que el Tribunal, sin embargo, exigió que dichas "resoluciones" se dictaran en procedimientos contradictorios. ${ }^{17}$ El Tribunal desarrolló posteriormente esa jurisprudencia, por ejemplo en los casos Van Uden ${ }^{18}$ y Mietz ${ }^{19}$. Con la refundición del Reglamento Bruselas I en 2012, la cuestión quedó por fin expresamente regulada. Se añadió una norma específica que establece las condiciones para el reconocimiento y la ejecución de las medidas provisionales y cautelares (artículo 2,

13 Considerando 10 del Reglamento sobre las consecuencias patrimoniales de las uniones registradas.

14 A partir del 8 de junio de 2021, los Estados miembros participantes son: Bélgica, Bulgaria, República Checa, Alemania, Grecia, España, Francia, Croacia, Italia, Luxemburgo, Malta, Países Bajos, Austria, Portugal, Eslovenia, Finlandia, Suecia y Chipre.

15 Reglamento (UE) n ${ }^{\circ}$ 1215/2012 del Parlamento Europeo y del Consejo, de 12 de diciembre de 2012, relativo a la competencia judicial, el reconocimiento y la ejecución de resoluciones judiciales en materia civil y mercantil (refundición) [2012] DO L351.

16 Para más información sobre las autoridades emisoras, véase la siguiente sección.

17 Case 125/79, Bernard Denilauler v SNC Couchet Frères, ECLI:EU:C:1980:130.

18 Case C-391/95, Van Uden Maritime BV, trading as Van Uden Africa Line v Kommanditgesellschaft in Firma DecoLine and Another, ECLI:EU:C:1998:543.

19 Case C-99/96, Hans-Hermann Mietz v Intership Yachting Sneek BV, ECLI:EU:C:1999:202. 
apartado 1, letra a), del Reglamento de Bruselas I bis). A saber, además de la necesidad de que el demandado sea "citado a comparecer" o al menos se le notifique la resolución antes de la ejecución, dichas medidas debían ser dictadas por el tribunal competente en cuanto al fondo del asunto. Dado que el Reglamento de los gemelos no aborda expresamente las medidas provisionales y cautelares en el contexto del reconocimiento y la ejecución de las resoluciones, puede establecerse una analogía con el régimen de Bruselas. ${ }^{20}$

Esto significa que las medidas provisionales y cautelares dictadas sobre la base del artículos 19 de los Reglamentos gemelos por órganos jurisdiccionales distintos del órgano jurisdiccional competente para juzgar el fondo del litigio, sólo tendrán efectos en el Estado miembro de origen. Esto evita una especie de "búsqueda de foro" para las medidas provisionales y cautelares, en la que las partes podrían buscar un Estado miembro en el que pudieran obtener una medida a su favor, aunque dicho Estado no tuviera ninguna relación real con el litigio, y luego solicitar la ejecución de la medida bien en el Estado miembro en el que se sustanciara el procedimiento en cuanto al fondo (pero en el que no pudiera obtenerse una medida similar) o bien en otro Estado miembro.

Además, el demandado debe tener la posibilidad de participar en el procedimiento para la emisión de la medida provisional o cautelar, o bien ser notificado de la existencia de dicha medida antes de la ejecución. Esto significa que el "efecto sorpresa" de las medidas provisionales y cautelares no puede obtenerse a través del régimen de circulación de decisiones de los Reglamentos gemelos.

La circulación transfronteriza de las transacciones judiciales y de los documentos públicos con fuerza ejecutiva se regula por separado de la de las "decisiones" y se describirá en el próximo capítulo de esta monografía. Sin embargo, hay que señalar que la cuestión de la caracterización no se evita del todo con las definiciones de los Reglamentos gemelos, especialmente a la luz de todos los diferentes efectos que las legislaciones nacionales confieren a estas dos categorías de documentos oficiales. En los documentos públicos, podría plantearse la cuestión de la delimitación de cuándo un notario ejerce funciones judiciales y cuándo no. En las transacciones judiciales, cabría preguntarse si no podrían entrar en la categoría de "decisiones" cuando producen, en el Estado miembro de origen, los mismos efectos que una sentencia, es decir, adquieren el efecto de cosa juzgada y son ejecutables del mismo modo que las sentencias. ${ }^{21}$ La redacción de los Reglamentos parece no permitir tal interpretación, sin embargo, consideramos que la cuestión es relevante, ya que los efectos reales de un documento oficial deben prevalecer sobre su título a la hora de determinar el régimen de circulación transfronteriza.

20 Para la analogía entre los Reglamentos gemelos y el Reglamento Bruselas I bis, véase. M. Andrae, Internationales Familienrecht, Nomos, Baden Baden, 2019, p. 402.

21 Este es el caso, por ejemplo, de Eslovenia, donde las transacciones judiciales tienen los mismos efectos que las sentencias definitivas (no existe un recurso ordinario, sino uno extraordinario, el "recurso de anulación de una transacción judicial" (Sl. tožba za razveljavitev sodne poravnave), en virtud de los artículos 392 y 393 de la Ley de Procedimiento Civil de Eslovenia (Zakon o pravdnem postopku), versión consolidada, Boletín Oficial de la República de Eslovenia, ${ }^{\circ} 73 / 2007$, con nuevas modificaciones. En virtud de las normas nacionales eslovenas, una transacción judicial extranjera se reconoce y se ejecuta con arreglo a las mismas normas que una sentencia extranjera (artículo 94, apartado 2, de la Ley de Derecho y Procedimiento Internos Privados (Zakon o mednarodnem zasebnem pravu in postopku), Boletín Oficial de la República de Eslovenia, nº 56/1999, con nuevas modificaciones. 


\section{2. Órganos jurisdiccionales}

El considerando 29 del Reglamento sobre el régimen económico matrimonial exige el respeto de los diferentes sistemas de tratamiento de las cuestiones relativas al régimen económico matrimonial en los Estados miembros. A los efectos del Reglamento, "el término "órgano jurisdiccional" debe tener, por tanto, un significado amplio, de modo que abarque no sólo a los órganos jurisdiccionales en sentido estricto, que ejercen funciones judiciales, sino también, por ejemplo, a los notarios de algunos Estados miembros que, en determinadas materias del régimen económico matrimonial, ejercen funciones judiciales como los órganos jurisdiccionales, y a los notarios y profesionales del Derecho que, en algunos Estados miembros, ejercen funciones judiciales en un determinado régimen económico matrimonial por delegación de un órgano jurisdiccional". El artículo 3, apartado 2, del Reglamento sobre el régimen económico matrimonial establece que, a efectos del Reglamento, el término "tribunal" designa a toda autoridad judicial y a todas las demás autoridades y profesionales del Derecho competentes en materia de regímenes económicos matrimoniales que ejerzan funciones jurisdiccionales o actúen por delegación de poderes de una autoridad judicial o bajo su control, siempre que estas otras autoridades y profesionales del Derecho ofrezcan garantías en materia de imparcialidad y de derecho de todas las partes a ser oídas, y siempre que sus decisiones, con arreglo a la legislación del Estado miembro en el que actúan (a) puedan ser objeto de recurso o revisión por parte de una autoridad judicial; y (b) tengan una fuerza y efectos similares a los de una decisión de una autoridad judicial sobre el mismo asunto". El Reglamento sobre los efectos patrimoniales de las uniones registradas contiene una norma idéntica relativa a los bienes de las uniones registradas.

La característica que define al "tribunal" es, por tanto, el ejercicio de funciones judiciales, y no el nombre o el tipo de autoridad que ejerce dichas funciones. El tipo más común de autoridades, que no son tribunales en el sentido estricto del término, pero que pueden, en muchos Estados miembros, ejercer (también) funciones judiciales, son los notarios, que también se mencionan expresamente en el Reglamento. El considerando 30 de los Reglamentos explica además que el Reglamento no interfiere con las competencias de los notarios en virtud de la legislación nacional. Sin embargo, es importante que cuando los actos notariales entren en el ámbito de aplicación del Reglamento, los notarios respeten las normas jurisdiccionales establecidas por el Reglamento.

Los Estados miembros debían notificar a la Comisión las demás autoridades y profesionales del derecho mencionados anteriormente. ${ }^{22}$ Mientras que los notarios se unen con frecuencia a los tribunales en asuntos de sucesión, las notificaciones muestran de forma interesante que sólo Portugal y la República Checa confieren poderes judiciales a los notarios en el ámbito de las relaciones patrimoniales de las parejas. Algunos Estados miembros notificaron otras profesiones, por ejemplo, Italia notificó “abogados y registradores civiles que actúan en el marco del procedimiento de negociación asistida (negoziazione assistita)". ${ }^{23}$ Sin embargo, la mayoría de los países participantes notificaron que

22 A 10 de junio de 2021, Malta y Eslovenia aún no han enviado sus notificaciones.

23 Suecia notificó a los "albaceas (bodelningsförrättare), a los administradores de fincas (boutred-ningsman) $\mathrm{y}$, en los procedimientos sumarios relativos a los requerimientos de pago o a la asistencia, a la Autoridad de Ejecución (Kronofogdemyndigheten). Portugal notificó (además de a los notarios) a las oficinas del registro civil (Conservatórias do Registo Civil). Finlandia notificó al "ejecutor". 
ninguna otra profesión o autoridad, aparte de los tribunales, era competente para dictar resoluciones en el sentido de los Reglamentos. ${ }^{24}$

\section{3. Ámbito de aplicación territorial y temporal}

Al haber sido adoptadas dentro del sistema de cooperación reforzada, las normas sobre reconocimiento y ejecución de resoluciones de los Reglamentos gemelos sólo se aplican en los Estados miembros que participan en la cooperación reforzada, y sólo a las resoluciones dictadas en los Estados miembros participantes. Si una resolución se origina en un Estado miembro de la UE que no participa en la cooperación reforzada o se exige el reconocimiento y la ejecución en dicho Estado miembro, se aplican las normas nacionales sobre reconocimiento y ejecución de resoluciones extranjeras, al igual que en el caso de una resolución de un Estado no perteneciente a la UE. En aras de la claridad, esta limitación del ámbito de aplicación territorial de los Reglamentos no se repite en todo el capítulo, y el término Estados miembros se utiliza para referirse a los Estados miembros participantes.

En cuanto al ámbito de aplicación temporal, los Reglamentos gemelos se aplican al reconocimiento y la ejecución de las resoluciones dictadas en procedimientos judiciales iniciados a partir del 29 de enero de 2019. Es importante destacar que la fecha importante es la del inicio del procedimiento judicial y, en principio, no la fecha de emisión de la sentencia. No obstante, el Reglamento permite el reconocimiento y la ejecución de las resoluciones dictadas después de su entrada en vigor, en virtud de sus normas, incluso en el caso de que el procedimiento se haya iniciado antes de su entrada en vigor, si la competencia del tribunal competente se basó en una norma conforme a las normas de competencia del Reglamento. ${ }^{25}$

\section{4. Ámbito de aplicación material}

El ámbito de aplicación material relevante para el reconocimiento y la ejecución de las resoluciones se establece en los artículos 1 y 3 del Reglamento, mientras que los considerandos también son de ayuda para la interpretación. El término "matrimonio" no se define en el Reglamento UE $n^{\circ}$ 2016/1103 de régimen económico matrimonial y debe interpretarse con arreglo a las legislaciones nacionales de los Estados miembros participantes (véase el considerando 17). Asimismo, de acuerdo con el considerando 64 de dicho Reglamento “[e]1 reconocimiento y la ejecución de una decisión sobre el régimen económico matrimonial en virtud del presente Reglamento no deben implicar en modo alguno el reconocimiento del matrimonio subyacente al régimen económico matrimonial que dio lugar a la decisión". El apartado 2 del artículo 1 del Reglamento excluye expresamente de su ámbito de aplicación "la existencia, la validez o el reconocimiento de un matrimonio". El Reglamento UE n ${ }^{\circ}$ 2016/1104 sobre los efectos patrimoniales de las uniones registra-

24 Estos son: Bélgica, Croacia, España, Chipre, Países Bajos, Bulgaria, Grecia, Francia, Luxemburgo y Austria.

25 Este sistema es análogo al del Reglamento Bruselas I de 2000. Para más información sobre las dudas que surgen en relación con este sistema, véase J. Kramberger Škerl, 'The application 'ratione temporis' of the Brussels I regulation (recast)' in D. Duić and T. Petrašević (eds), EU and Comparative Law Issues and Challenges: Procedural Aspects of EU Law, Faculty of Law Osijek, Osijek, 2017, pp. 341-363, <www.pravos.unios.hr/download/eu-andcomparative-law-issues-and-challenges.pdf $>$ accessed 06.07.2021. For more on the rules on jurisdiction in the Matrimonial Property Regimes Regulation, see N. Pogorelčnik Vogrinc, 'Mednarodna pristojnost v sporih glede premoženjskih razmerij med zakoncema' (2020) 1 Podjetje in delo, 178-203. 
das, en cambio, define las "uniones registradas" como "el régimen de vida en común de dos personas previsto por la ley, cuya inscripción es obligatoria en virtud de ésta y que cumple las formalidades legales exigidas por dicha ley para su creación". Sin embargo, el Reglamento tampoco se aplica a la existencia, la validez o el reconocimiento de una unión registrada (apartado 2 del artículo 1), y el considerando 63 de dicho Reglamento establece: "El reconocimiento y la ejecución de una decisión sobre los efectos patrimoniales de una unión registrada en virtud del presente Reglamento no deben implicar en modo alguno el reconocimiento de la unión registrada que dio lugar a la decisión."

Debido a estas exclusiones, puede ocurrir que un Estado miembro participante aplique uno de los Reglamentos para determinar la competencia, pero que otro Estado miembro no reconozca la siguiente sentencia en virtud del mismo Reglamento; se aplicará el otro de los Reglamentos gemelos, o incluso la ley nacional. ${ }^{26} \mathrm{Si}$ la sentencia comprende decisiones sobre varias cuestiones, sólo las relativas a las relaciones patrimoniales entre los cónyuges o las parejas registradas son reconocidas y forzadas en virtud de los Reglamentos gemelos. ${ }^{27}$

\section{RECONOCIMIENTO}

Las normas de reconocimiento de los Reglamentos gemelos imitan el sistema del Reglamento Bruselas I de 2000, ${ }^{28}$ adoptado posteriormente (con algunas excepciones notables) en el Reglamento sobre sucesiones y el Reglamento sobre alimentos. Esto es muy positivo, ya que los profesionales y las legislaturas de los Estados miembros tienen experiencia en el tratamiento de dichas normas. Además, es importante que la jurisprudencia del TJUE y de los tribunales nacionales, adoptada sobre la base del Reglamento de Bruselas I (y, antes, del Convenio de Bruselas), pueda servir de instrumento de interpretación. ${ }^{29}$

El reconocimiento de las sentencias de otros Estados miembros es, por tanto, "automático" (ipso iure), por ejemplo, sin necesidad de realizar comprobaciones en el Estado miembro de reconocimiento. Los efectos de la resolución, emitida en un Estado miembro participante, se amplían automáticamente a otros Estados miembros participantes. En los demás Estados miembros participantes, la fuerza vinculante de dicha resolución es igual a la de las resoluciones domésticas (¡pero no más amplia que en el Estado miembro de origen!).

Sin embargo, existe una diferencia entre una resolución de otro Estado miembro participante y una sentencia nacional. En concreto, la "presunción de regularidad" 30 de

26 Cf. M. Andrae, above n. 23, p. 401, que pone el ejemplo de que el tribunal del Estado miembro de origen de la sentencia se desentiende de su competencia sobre la base del Reglamento sobre los bienes matrimoniales, pero el Estado miembro de ejecución ejecuta la sentencia en virtud del Reglamento sobre las consecuencias patrimoniales de las uniones registradas.

27 Si, por ejemplo, la sentencia comprende una decisión sobre la pensión alimenticia, así como una decisión sobre la división de los bienes comunes de los cónyuges divorciados, la primera parte se reconocerá y se ejecutará en virtud del Reglamento sobre la pensión alimenticia, y la segunda en virtud del Reglamento sobre los bienes matrimoniales. Cf. ibid.

28 Reglamento (CE) n ${ }^{\circ}$ 2001/44 del Consejo, de 22 de diciembre de 2000, relativo a la competencia judicial, el reconocimiento y la ejecución de resoluciones judiciales en materia civil y mercantil [2001] DO L12.

29 Cf. U. Bergquist in U. Bergquist, D. Damascelli, R. Frimston, P. Lagarde and B. Reinhartz, The EU Regulations on Matrimonial Property, Oxford University Press, Oxford (2019), p. 140.

30 Cf. M. Andrae, aboven. 23, p. 401, who speaks about a 'legal presumption in favour of recognition' (Rechtsvermutung zu Gunsten der Anerkennung). 
una resolución de otro Estado miembro es refutable, si se demuestra que existen motivos para volver a denegar el reconocimiento.

Con el fin de garantizar la seguridad jurídica de la parte que confía en la eficacia de la resolución extranjera, la "presunción de regularidad" puede confirmarse en los procedimientos especiales de reconocimiento previstos en los Reglamentos, de modo que sea irrefutable (artículo 36.2 de los Reglamentos gemelos). Este procedimiento se lleva a cabo conforme a las normas del procedimiento de otorgamiento de la ejecución previstas en el mismo Reglamento. La decisión de reconocimiento tiene carácter declarativo, ya que la resolución produce efectos en todos los Estados miembros al mismo tiempo que en el Estado miembro de origen. ${ }^{31}$ La parte contraria en estos procedimientos puede invocar motivos de denegación de reconocimiento y, en caso de éxito, impedir que la sentencia extranjera surta efectos en el país requerido.

A diferencia del otorgamiento de la ejecución, el reconocimiento también puede (y en la mayoría de los casos así se hará) decidirse como una cuestión preliminar en el procedimiento sobre otro asunto principal (reconocimiento incidental, artículo 36/3 de los Reglamentos gemelos). En tal caso, todo tribunal competente en el asunto principal puede decidir también sobre el reconocimiento de una resolución extranjera cuyos efectos se hayan invocado en el procedimiento. Este reconocimiento, a su vez, sólo es definitivo (irrebatible) en dicho procedimiento y no erga omnes (por ejemplo, aún puede adoptarse una decisión diferente en el procedimiento de reconocimiento autónomo mencionado anteriormente o en otros procedimientos incidentales).

Al igual que en el Reglamento de Bruselas I, los Reglamentos gemelos no prevén una solicitud de no reconocimiento, que podría, en algunos casos, ser interesante para una de las partes del procedimiento original (el Reglamento de Bruselas II bis, por ejemplo, prevé dicha opción en el artículo 21, apartado 3). ${ }^{32}$ Así, la parte que considera que existen motivos de denegación, debe esperar a que la otra parte haga valer los efectos de la resolución en otro Estado miembro, para poder oponerse y exigir la denegación del reconocimiento.

Si se incoa un procedimiento autónomo de reconocimiento, el tribunal competente puede suspender el procedimiento si "se ha interpuesto un recurso ordinario contra la resolución en el Estado miembro de origen” (artículo 41 de los Reglamentos gemelos). Según la jurisprudencia del TJUE relativa al Convenio de Bruselas, el término "recurso ordinario" debe interpretarse de forma autónoma. ${ }^{33}$ La consecuencia lógica de esta disposición reglamentaria es que las sentencias, contrariamente a lo que exigen numerosos ordenamientos jurídicos nacionales, no tienen que ser definitivas (res judicata) para poder

31 T. Ivanc in M. Repas and V. Rijavec (eds), Mednarodno zasebno pravo Evropske unije, Uradni list, Ljubljana (2018), p. 554, U. Bergquist, above n. 33, pp. 144, 146.

32 La misma opción se contempla en el artículo 30.3 del Reglamento Bruselas II ter (Reglamento (UE) 2019/1111 del Consejo, de 25 de junio de 2019, relativo a la competencia, el reconocimiento y la ejecución de resoluciones en materia matrimonial y de responsabilidad parental, y a la sustracción internacional de menores (refundición) [2019] DO L178).

33 En la sentencia Industrial Diamond, el TJUE declaró “Todo recurso que pueda dar lugar a la anulación o a la modificación de la resolución objeto del procedimiento de reconocimiento o de ejecución en virtud del Convenio y cuya interposición esté vinculada, en el Estado en el que se haya dictado la resolución, a un plazo fijado por la ley y que comience a correr en virtud de esa misma resolución, constituye un "recurso ordinario" (...)", asunto 43/77, Industrial Diamond Supplies contra Luigi Riva, ECLI:EU:C:1977:188.. 
ser reconocidas en virtud del Reglamento. ${ }^{34} \mathrm{El}$ "destino" del procedimiento suspendido lo determina el derecho nacional del Estado miembro de reconocimiento y no lo aborda el Reglamento. Indudablemente, si la resolución se anula en el Estado miembro de origen, el procedimiento de reconocimiento debe terminar, dado que el reconocimiento sólo debe "ampliar" los efectos de la resolución que existen en el Estado miembro de origen y una resolución no puede producir más efectos en el extranjero que en su país de origen. ${ }^{35}$

\section{LA DECLARACIÓN DE EJECUTORIEDAD (EXEQUATUR)}

Los Reglamentos gemelos permiten la ejecución de las resoluciones judiciales de otros Estados miembros, si dichas resoluciones son ejecutivas en el Estado miembro de origen y si fueron declaradas ejecutivas en el Estado miembro de ejecución.

Los Reglamentos establecen varias normas de procedimiento que deben respetarse en los procedimientos de solicitud de otorgamiento de la ejecución, pero dejan una amplia autonomía a las legislaciones nacionales para regular otras cuestiones de procedimiento. La información sobre algunas de estas cuestiones (por ejemplo, la competencia de los tribunales y otras autoridades de los Estados miembros y el tipo y la disponibilidad de los recursos legales) está disponible en todas las lenguas oficiales de la UE en el sitio web del Atlas Judicial Europeo en materia civil, en las pestañas Matrimonial y Consecuencias patrimoniales de las uniones registradas. ${ }^{36}$ Hay que subrayar que las normas nacionales sólo pueden complementar las normas de los Reglamentos; si bien es evidente que las normas de los Reglamentos tienen un valor jerárquico superior a cualquier disposición nacional sobre la misma materia, también es importante que las disposiciones nacionales complementarias no priven a las normas de la UE de su pleno efecto (effet utile) (así, por ejemplo, la legislación nacional no puede prever motivos adicionales de denegación de la declaración de ejecutoriedad además de los previstos por los Reglamentos). ${ }^{37}$

\subsection{La adminisibilidad de la solicitud de exequatur}

La solicitud de declaración de ejecutoriedad debe presentarse ante el tribunal o la autoridad competente del Estado miembro de ejecución, que dicho Estado miembro comunicó a la Comisión. Así, por ejemplo, Italia comunicó la competencia de la Corte de Apelación (Corte di Appello), España la del Juzgado de Primera Instancia (Juzgado de Primera instancia), Croacia la del tribunal municipal (općinski sud) y Eslovenia la del tribunal

34 Cf. T. Franzmann and Th. Schwerin in R. Geimer and R. Schütze (eds), Europäische Erbrechtsverordnung, C.H. Beck, Munich (2016), p. 364.

35 Esta norma fundamental en el ámbito del reconocimiento y la ejecución de las resoluciones extranjeras ya se mencionó en el "Informe Jenard" relativo al Convenio de Bruselas de 1968. Jenard Report on the Convention on jurisdiction and the enforcement of judgments in civil and commercial matters (Signed at Brussels, 27 September 1968) [1979] OJ C59, p. 43. It was later endorsed by the CJEU case law, eg in Case 145/86, Horst Ludwig Martin Hoffmann v Adelheid Krieg, ECLI:EU:C:1988:61, and Case C-420/07, Meletis Apostolides v David Charles Orams, Linda Elizabeth Orams, ECLI:EU:C:2009:271.

36 Https://e-justice.europa.eu/content_european_judicial_atlas_in_civil_matters-321-en.do. Toda la información sobre los sistemas jurídicos nacionales, si no se indica lo contrario, se ha consultado en este sitio we.

37 Véase, por ejemplo, la sentencia del TJUE en el asunto C-157/12, Salzgitter Mannesmann Handel GmbH contra SC Laminorul SA, ECLI:EU:C:2013:597 (en relación con el Reglamento Bruselas I), donde el Tribunal sostuvo que: "la lista de motivos de inaplicación es exhaustiva". 
de distrito (okrožno sodišče). ${ }^{38}$ La competencia territorial (local) se determina en el Reglamento y corresponde al tribunal del domicilio de la parte contra la que se solicita la ejecución, o al tribunal del lugar de ejecución. ${ }^{39}$ La determinación del domicilio se realiza con arreglo a la legislación nacional del Estado miembro de ejecución. ${ }^{40}$ Puede ser útil señalar que esta noción es diferente de la de "residencia habitual" en los capítulos del Reglamento que se refieren a la jurisdicción y a la ley aplicable y que debe interpretarse de forma autónoma. ${ }^{41}$

Los Reglamentos se oponen a que los Estados obliguen al demandante a tener una dirección postal o un representante autorizado en el Estado miembro de ejecución. Para facilitar la notificación de documentos judiciales, muchas normas procesales civiles nacionales prevén esta obligación para las partes con domicilio en el extranjero. ${ }^{42}$ En la UE, sin embargo, el Reglamento de servicios ${ }^{43}$ facilita el servicio hacia y desde otros Estados miembros, por lo que se puede omitir la mencionada obligación procesal y ahorrar así tiempo y dinero. Por otra parte, aunque los Reglamentos pretenden evidentemente simplificar el procedimiento para el solicitante liberándolo de la representación obligatoria, es muy probable que la mayoría de los solicitantes opten por ser representados por un abogado en el Estado miembro de ejecución. El procedimiento se llevará a cabo en la lengua de ese Estado (lo que constituye una importante cuestión práctica, a pesar de la traducción) y la lex fori, más conocida por los abogados "nacionales", determinará muchas cuestiones procesales importantes. Así, las cuestiones de la representación y del domicilio para la notificación están, en la mayoría de los casos, conectadas, ya que muchas legislaciones nacionales prevén que la notificación se haga al abogado (únicamente). ${ }^{44}$

En los Reglamentos gemelos se determinan varios requisitos previos que el solicitante debe cumplir para que la solicitud sea admisible. El solicitante debe aportar (i) una copia de la resolución que cumpla las condiciones necesarias para establecer su autenticidad; y (ii) el certificado emitido por el tribunal o la autoridad competente del Estado miembro de origen utilizando el formulario adecuado. ${ }^{45} \mathrm{Si}$ el solicitante no presenta este último formulario, el tribunal puede fijar un plazo para su presentación o incluso decidir sobre la solicitud sin dicho formulario, si el solicitante presenta un "documento equiva-

38 En junio de 2021, Eslovenia aún no ha comunicado los tribunales competentes sobre la base del Reglamento de Regímenes Patrimoniales. Sin embargo, dado que el procedimiento es idéntico al del Reglamento de sucesiones y al del Reglamento "original” de Bruselas I, consideramos que los mismos tribunales deberían ser competentes.

39 El momento relevante para valorar el domicilio del demandado es el de la presentación de la demanda de exequátur; cualquier cambio de domicilio posterior es irrelevante (perpetuatio fori). U. Bergquist, above n. 33, p. 188.

40 Por ejemplo, en Eslovenia será la llamada "residencia permanente" (stalno prebivališče) y en Alemania la llamada "residencia ordinaria" (Wohnsitz), como se indica en las traducciones de los tres reglamentos al esloveno y al alemán.

41 U. Bergquist, above n. 33, p. 185.

42 Véase, por ejemplo, el artículo 146 del Código de Procedimiento Civil de Eslovenia (Zakon o pravdnem postopku), Boletín Oficial de la República de Eslovenia, nº 26/1999, en su versión modificada.

43 Reglamento (CE) n 2007/1393 del Parlamento Europeo y del Consejo, de 13 de noviembre de 2007, relativo a la notificación y al traslado en los Estados miembros de documentos judiciales y extrajudiciales en materia civil o mercantil (notificación y traslado de documentos) y por el que se deroga el Reglamento (CE) n 2000/1348 del Consejo [2007] DO L324.

44 Véase, por ejemplo, el artículo 137(1) del Código de Procedimiento Civil de Eslovenia.

45 Anexo I del Reglamento de Ejecución (UE) 2018/1935 de la Comisión, de 7 de diciembre de 2018, por el que se establecen los formularios a los que se refiere el Reglamento (UE) 2016/1103 del Consejo por el que se establece una cooperación reforzada en el ámbito de la competencia, la ley aplicable, el reconocimiento y la ejecución de resoluciones en materia de regímenes económicos matrimoniales [2018] DO L314. 
lente" o si el tribunal considera que tiene suficiente información para decidir. Se trata de una decisión sensata del legislador europeo, ya que el certificado no forma parte de la sentencia y pretende simplificar el trabajo del tribunal en el Estado miembro de ejecución al proporcionar la información más importante sobre la sentencia en un formulario que es idéntico en todas las lenguas oficiales de la UE y que, por tanto, no necesita traducción. ${ }^{46}$ Sin embargo, si el tribunal tiene la información necesaria para su decisión, insistir en el formulario oficial sería superfluo. La traducción y/o transliteración de los documentos no es obligatoria, pero está sujeta a la demanda del tribunal. En caso de que se produzca dicha demanda, es muy importante subrayar que el tribunal sólo debe volver a solicitar la traducción del texto insertado en el formulario por la autoridad extranjera, y no del propio formulario, ya que éste ya está disponible en todas las lenguas oficiales de la UE. Por lo tanto, el traductor debe utilizar el formulario disponible en la lengua de destino e insertar la traducción del texto añadido. Ni que decir tiene que sólo la traducción del texto añadido puede facturarse y considerarse un coste procesal justificado.

Si se requiere una traducción, ésta debe ser realizada por "una persona cualificada para realizar translaciones en uno de los Estados miembros" (artículo 46.2). Por lo tanto, el tribunal no puede exigir que la traducción sea realizada necesariamente por un traductor del Estado miembro de ejecución, sino que debe aceptar una traducción realizada por un traductor "cualificado" en otro Estado miembro. El Reglamento no define más el término "cualificado" y la doctrina está dividida en cuanto a la cuestión de si el traductor debe tener una autorización oficial para traducir documentos jurídicos. Dado que la calidad de la traducción tiene una importancia crucial en los litigios transfronterizos, algún autor ${ }^{47}$ opina que el traductor debe cumplir la condición de traducir documentos judiciales según el derecho nacional de su Estado de origen.

\subsection{Procedimientos en primera instancia}

El procedimiento para el otorgamiento de la ejecución es, en principio, unilateral (ex parte). Por lo tanto, no se notifica a la parte contraria la presentación de la solicitud. El tribunal sólo verifica el cumplimiento de los requisitos formales de los Reglamentos y de la legislación procesal nacional (por ejemplo, en relación con la representación de los menores). Es muy importante destacar que el tribunal no verifica de oficio ninguno de los motivos de denegación de la ejecución, a saber, la contradicción con el orden público del Estado miembro de ejecución, la falta de notificación del escrito introductorio del procedimiento y la irreconciliabilidad de las resoluciones.

Si se cumplen los requisitos de admisibilidad, el tribunal declara la sentencia ejecutiva. Esta decisión se notificará a ambas partes. El Reglamento establece que el tribunal debe notificar a la parte contraria ("la parte contra la que se solicita la ejecución") también la resolución, si ésta aún no ha sido notificada a dicha parte. Puede sorprender que el Reglamento contemple la posibilidad de que la resolución no haya sido notificada al demandado, ya que la ejecutoriedad suele ser consecuencia de dicha notificación. ${ }^{48}$ En

46 También es posible invocar en el procedimiento de exequátur que el contenido del formulario es erróneo. Cf. TJUE, asunto n. C-619/10, Trade Agency Ltd contra Seramico Investments Ltd. ECLI:EU:C:2012:531. Así, la presunción de regularidad queda desvirtuada: U. Bergquist, above n. 33, p. 192.

47 U. Bergquist, above n. 33, p. 195.

48 Sin embargo, este no es el caso en todos los Estados miembros: U. Bergquist, above n. 33, p. 200. 
estos casos, el demandado podrá invocar que no ha podido agotar todas las vías de recurso en el Estado miembro de origen y, por tanto, podrá hacer valer determinados motivos de denegación, entre los que destaca la falta de notificación del documento introductorio en el procedimiento (artículo 37 b) de los Reglamentos gemelos) si tampoco se le ha notificado dicho documento.

Como es habitual en el ámbito del reconocimiento y la ejecución de las resoluciones extranjeras, el Reglamento también prevé la ejecución parcial. Esta ejecución parcial puede concederse bien a petición del solicitante o de oficio, "cuando se haya dictado una resolución sobre varios asuntos y no pueda concederse la ejecución para todos ellos". Por ejemplo, la ejecutoriedad parcial puede ser consecuencia del hecho de que los motivos de denegación sólo existen en relación con determinadas partes de la resolución, o bien porque determinadas partes de la resolución quedan fuera del ámbito de aplicación del Reglamento (en este último caso, se dictarán dos o más resoluciones parciales de ejecutoriedad por motivos de actos jurídicos diferentes). ${ }^{49}$ Para que la ejecución parcial sea posible, la sentencia debe ser "divisible". ${ }^{50}$

\subsection{Recurso(s) contra el otorgamiento de la ejecución}

Contra el auto de ejecución cabe al menos un recurso. Puede ser interpuesto por cualquiera de las partes, en función del resultado del procedimiento con la solicitud. El procedimiento con el recurso debe garantizar la posibilidad de participación de ambas partes (principio de contradicción).

Los Estados miembros debían comunicar los tribunales competentes para la resolución de dicho recurso. Por ejemplo, Italia comunicó la competencia del Tribunal Supremo de Casación (Suprema Corte di Cassazione), España la competencia de la Audiencia Provincial (Audiencia Provincial), Croacia la competencia de los tribunales municipales y Eslovenia la competencia de los tribunales de distrito. La decisión de Eslovenia y Croacia de designar a los mismos tribunales como competentes para el procedimiento de exequátur y para el recurso de apelación puede parecer sorprendente, pero se ajusta al sistema establecido en las legislaciones nacionales de estos países en relación con los procedimientos de reconocimiento de sentencias extranjeras. ${ }^{51}$ En Eslovenia, la primera fase (unilateral) del procedimiento es tramitada por un solo juez, y la (primera) apelación por un panel de tres jueces del mismo tribunal de primera instancia.

El plazo para presentar un recurso es de 30 días a partir de la notificación de la declaración de ejecutoriedad (o de la denegación de dicha declaración) para los recurrentes domiciliados en el Estado miembro de ejecución, y de 60 días para los recurrentes domiciliados en otro Estado miembro. No puede concederse ninguna prórroga de este

49 U. Bergquist, above n. 33, pp. 219, 220.

50 U. Bergquist, above n. 33, p. 221. La "divisibilidad" de la resolución significa que su parte dispositiva puede dividirse en dos o más partes independientes, por ejemplo, hay una obligación de pagar una determinada suma de dinero y una obligación de entregar un bien específico: si la resolución relativa al dinero no pasa el control en el Estado miembro de ejecución (es decir, si existen uno o más motivos de denegación), la resolución sobre la entrega del bien podrá seguir ejecutándose, si no existen motivos de denegación respecto a esa parte.

51 En el caso de Eslovenia, véase, por ejemplo, J. Kramberger Škerl, 'The recognition and enforcement of foreign judgments in Slovenia: national law and the Brussels I (recast) Regulation’ (2018/19) 20 Yearbook of Private International Law, 281-314. 
plazo por razón de la distancia (pero puede concederse por otros motivos, si la legislación nacional del Estado miembro de ejecución lo prevé). Los Reglamentos gemelos no mencionan expresamente a los solicitantes domiciliados en terceros Estados. Bergquist, citando a varios autores, considera que el plazo de 30 días se aplica en esos casos, pero que puede concederse una prórroga en virtud del Derecho nacional. ${ }^{52}$

Los Estados miembros tienen la posibilidad de conceder otro recurso (aunque no más de uno), que sin embargo no es obligatorio. Por ejemplo, Italia, España y Eslovenia prevén este recurso adicional ante los tribunales nacionales superiores. Croacia, sin embargo, no prevé un segundo recurso en virtud de los Reglamentos gemelos, pero sí en virtud del Reglamento de sucesiones (que, curiosamente, es resuelto por el tribunal de primera instancia si decide modificar la decisión, o bien por el tribunal de segunda instancia).

La existencia de los motivos de denegación del otorgamiento de la ejecución (artículos 37, 38 y 39 de los Reglamentos gemelos) será comprobada en primer lugar por el tribunal en el procedimiento de recurso. Además, pueden ser examinados en el marco del segundo recurso, si éste está previsto en el Estado miembro de ejecución. Si se comprueba la existencia de un motivo de denegación, el tribunal tiene que denegar el reconocimiento o el otorgamiento de la ejecución y no dispone de discrecionalidad para hacerlo o no. ${ }^{53}$ Los Reglamentos exigen que los tribunales resuelvan los recursos sin demora, aunque, como suele ocurrir con las actuaciones de los tribunales, no se fija ningún plazo concreto.

Se ofrece otra garantía para el demandado. Si en el país de origen se suspende la ejecución de la resolución por haberse interpuesto un recurso suspensivo, el tribunal que resuelve el primer o segundo recurso contra el otorgamiento de la ejecución suspende el procedimiento a petición de la parte contraria (artículo 52 de los Reglamentos gemelos). A diferencia del procedimiento de reconocimiento, en el que la suspensión es facultativa, dicha suspensión es obligatoria en el procedimiento de exequátur, si la parte contraria lo solicita. El tribunal esperará así el resultado del procedimiento en el Estado de origen, ya que, al igual que en el caso del reconocimiento, una resolución no puede producir más efectos en el Estado de ejecución que en el Estado de origen, es decir, no puede ser ejecutable en otro Estado, si no lo es en el Estado de origen.

\subsection{Medidas provisionales o cautelares, antes y durante el procedimiento de exequatur}

Los Reglamentos gemelos prevén que la persona que solicite el otorgamiento de la ejecución disponga de medidas provisionales, incluso cautelares (ofrecidas por la ley del Estado de ejecución $)^{54}$, antes de que se adopte una decisión definitiva al respecto. El demandante puede solicitar medidas cautelares incluso antes de presentar una solicitud de declaración de ejecutoriedad, basándose en que la resolución ya ha sido reconocida automáticamente en el Estado miembro de la futura o posible ejecución (artículo 53, apartado 1, de los Reglamentos gemelos). El elemento menos previsible al que a menudo aspira el demandante estará garantizado si las medidas cautelares se conceden antes de que se noti-

52 U. Bergquist, above n. 33, p. 204.

53 N. Pogorelčnik Vogrinc, in M.J. Cazorla González, M. Giobbi, J. Kramberger Škerl, L. Ruggeri, S. Winkler, Property relations of cross border couples in the European Union, Edizioni Scientifiche Italiane, Naples (2020), p. 149.

54 U. Bergquist, above n. 33, pp. 216, 217. 
fique al demandado la resolución judicial sobre el otorgamiento de la ejecución, ya que el procedimiento con la solicitud de exequátur es en un principio unilateral y el demandado no suele tener conocimiento de él. Cuando el otorgamiento de la ejecución sea definitivo (por ejemplo, al finalizar el plazo para interponer el (primer) recurso o cuando la decisión sobre dicho recurso sea definitiva), el demandante tendrá acceso a la ejecución (real).

El artículo 53 de los Reglamentos gemelos se refiere, pues, al dictado de las medidas provisionales solicitadas en el Estado miembro de (la futura) ejecución sobre la base de la resolución de otro Estado miembro, del que se solicita o se solicitará la ejecución. Sin embargo, este artículo no priva de su efecto al artículo 19, que otorga competencia a los tribunales de cualquier Estado miembro para dictar medidas provisionales y cautelares. Sin embargo, las únicas medidas provisionales y cautelares que podrán circular en la UE y, por tanto, ser ejecutadas también en el Estado miembro de ejecución de la resolución sobre el fondo del litigio, son las dictadas en procedimientos contradictorios por el tribunal competente en cuanto al fondo del litigio (véase la sección sobre la interpretación del término "decisión").

\subsection{Costes del procedimiento de exequatur}

Dado que los costes de los procedimientos de exequátur pueden ser bastante elevados en algunos Estados miembros, ${ }^{55}$ es importante la disposición de los Reglamentos gemelos sobre la asistencia jurídica (artículo 55). Establece que el derecho del solicitante que se benefició de la asistencia jurídica gratuita o de la exención de costes o gastos en el procedimiento principal en el Estado miembro de origen de la resolución se "amplía" para abarcar también los procedimientos de declaración de ejecutoriedad en el Estado miembro de ejecución. ${ }^{56}$ Dado que los sistemas de asistencia jurídica difieren considerablemente, ${ }^{57}$ debe garantizarse la asistencia jurídica más amplia prevista por la legislación nacional del Estado miembro de ejecución (que no es necesariamente la misma en cuanto al fondo y/o al ámbito que la asistencia jurídica en el Estado miembro de origen). El solicitante debe afirmar y probar que se benefició de la asistencia jurídica en el Estado miembro de origen. ${ }^{58}$ El punto 7 del formulario de solicitud (anexo I de los reglamentos de aplicación) facilitado por la Comisión está dedicado a esta información.

Además, no se debe imponer al solicitante ningún depósito o precaución adicional (cautio judicatum solvi, cautio auctoris) por razón de su nacionalidad extranjera o de su domicilio en el extranjero. Esta norma abarca tanto el procedimiento de exequátur como la ejecución (real). ${ }^{59}$

55 Un estudio de los costes de los procedimientos de exequátur en virtud del Reglamento de Bruselas I reveló que el coste medio de un procedimiento de exequátur simple (es decir, el solicitante tiene éxito con la solicitud, no se presenta ningún recurso) fue de 2.208 euros en 2009; estos costes incluyen los costes de translación, los honorarios de los abogados y las tasas judiciales: Documento de trabajo de los servicios de la Comisión, SEC(2010) 1547 final, 14 de diciembre de 2010, p. 53.

56 Rudolf speaks of "the principle of continuity and extension of legal aid". C. Rudolf, in A. Deixler-Hübner and M. Schauer (eds), EuErbVO Kommentar zur Eu-Erbrechtsverordnung, Manz, Vienna (2015), p. 405.

57 No obstante, el derecho a la asistencia jurídica gratuita para quienes carecen de recursos suficientes para acceder efectivamente a la justicia debe garantizarse en todos los Estados miembros sobre la base del artículo 47/3 de la Carta de los Derechos Fundamentales de la UE [2012] DO C326.

58 U. Bergquist, above n. 33, p. 225.

59 U. Bergquist, above n. 33, p. 227 and other authors cited there. 
Es importante subrayar que los Reglamentos gemelos no prevén una "extensión" del derecho a la asistencia jurídica más allá de los procedimientos de reconocimiento (sobre la base del apartado 2 del artículo 36 de los Reglamentos gemelos) y exequátur, por ejemplo, los procedimientos regulados en estos actos. Si se necesita asistencia jurídica en el procedimiento de ejecución (real), se aplica plenamente el Derecho nacional del Estado de ejecución. ${ }^{60}$ Por otra parte, el hecho de que el solicitante no se haya beneficiado de la justicia gratuita en el Estado miembro de origen tampoco le impide solicitarla en el Estado miembro de ejecución con arreglo a la normativa nacional de dicho Estado. El principio de no discriminación en la concesión de la justicia gratuita en los litigios transfronterizos está consagrado en la Directiva de la UE sobre asistencia jurídica. ${ }^{61}$

En la mayoría de los Estados miembros se impone una tasa judicial por la incoación de un procedimiento exequatur. Los Reglamentos no excluyen estas tasas, aunque no deben calcularse por referencia al valor del asunto en cuestión, como es habitual en otros procedimientos judiciales. Los procedimientos transfronterizos suelen referirse a cuestiones de un valor no despreciable, al menos para las partes (de lo contrario, éstas no se molestarían en incoarlos), por lo que esta disposición es bienvenida. También está justificada, ya que la tarea de los tribunales consiste únicamente en comprobaciones formales (que pueden ser más o menos complicadas, sin relación con el valor del litigio original). Hay que subrayar que esta norma sólo se aplica a los "procedimientos de otorgamiento de la ejecución" (y, por analogía, tal y como se determina en el Reglamento, a los procedimientos de reconocimiento), pero no a otras fases del procedimiento de exequátur, ${ }^{62}$ ni a los procedimientos relativos a las medidas provisionales. ${ }^{63}$

Los Reglamentos gemelos sólo mencionan la asistencia jurídica para el solicitante, mientras que el demandado también podría necesitarla cuando interponga el o los recursos. Esta asistencia jurídica está regulada por el derecho nacional del Estado miembro de ejecución, naturalmente en lo que respecta a las normas supra nacionales mencionadas. ${ }^{64}$

\section{MOTIVOS DE DENEGACIÓN DE RECONOCIMIENTO Y EJECUCIÓN}

Los motivos de denegación del reconocimiento y del otorgamiento de la ejecución se regulan en el artículo 37 de los Reglamentos gemelos. Así pues, se prevén idénticos motivos de denegación en ambas situaciones, lo que debe tenerse en cuenta a lo largo de esta Sección. Dicho

60 U. Bergquist, above n. 33, p. 225 and other authors cited there.

61 Artículo 4 de la Directiva 2002/8/CE del Consejo, de 27 de enero de 2003, destinada a mejorar el acceso a la justicia en los litigios transfronterizos mediante el establecimiento de reglas mínimas comunes relativas a la justicia gratuita para dichos litigios [2003] DO L26.

62 El procedimiento con el recurso o los recursos ya no consiste únicamente en la comprobación de las formalidades, puesto que el solicitante ha de invocar motivos de denegación, algunos de los cuales (especialmente el motivo de orden público) pueden exigir un minucioso examen sustancial y procedimental de la autoridad de apelación (para más información al respecto, véase el capítulo dedicado a los motivos de denegación).

63 U. Bergquist, above n. 33, p. 229, y otros autores allí citados.

64 En su auto en el asunto n. C-156/12, GREP GmbH contra Freitstaat Bayern, ECLI:EU:C:2012:342, el TJUE decidió que el recurso contra el otorgamiento de la ejecución en virtud del Reglamento Bruselas I constituía un ejercicio del Derecho de la UE en el sentido del artículo 51 de la Carta de los Derechos Fundamentales de la UE, y que era aplicable la obligación de prestar asistencia jurídica gratuita del artículo 47, apartado 3, de la Carta. 
artículo establece que no se reconocerá la resolución si es manifiestamente contraria al orden público, si, en las resoluciones en rebeldía, no se ha notificado debidamente al demandado el escrito de interposición del recurso y si la resolución es inconciliable con una resolución ya existente dictada en el Estado miembro de ejecución o, en diversas condiciones, en otro Estado. Es importante señalar que estos son los únicos motivos de denegación que pueden aplicarse; los Estados miembros no pueden prever otros motivos de denegación adicionales. ${ }^{65}$

El artículo 38 establece además que el artículo 37 de los Reglamentos gemelos será aplicado por los tribunales y otras autoridades competentes de los Estados miembros respetando los derechos y principios fundamentales reconocidos en la Carta, en particular en su artículo 21 relativo al principio de no discriminación. El artículo 39 prohíbe la revisión de la competencia del tribunal de origen, así como la aplicación de la defensa del orden público a las normas de competencia establecidas en los artículos 4 a $12 .{ }^{66}$ Por último, el artículo 40 subraya la norma general de que, en ningún caso, una resolución dictada en un Estado miembro puede ser objeto de revisión en cuanto al fondo.

\subsection{La excepción de orden público}

De acuerdo con los Reglamentos gemelos, no se reconocerá una resolución si es manifiestamente contraria al orden público del Estado miembro en el que se solicita el reconocimiento. La cláusula de orden público es una norma jurídica que debe concretarse por los tribunales en cada caso individual. La doctrina y la jurisprudencia orientan la decisión, a veces difícil, de hasta qué punto una diferencia entre la solución adoptada por un juez extranjero o el procedimiento llevado a cabo en el extranjero, por un lado, y la opinión del derecho interno, por otro, es aceptable para el Estado de ejecución y en qué casos se convierte en inaceptable. En general, el orden público contiene valores fundamentales e intereses vitales del Estado requerido, que deben permanecer intactos para preservar la coherencia del orden jurídico y social de dicho Estado. Naturalmente, tales valores e intereses también abarcan los que se originan en los instrumentos jurídicos supranacionales y en la pertenencia de los Estados miembros a organizaciones internacionales, como la UE, el Consejo de Europa y otras. ${ }^{67}$

Al decidir sobre el reconocimiento y la ejecución de una sentencia extranjera, se habla de un "orden público atenuado" (ordre public attenué), lo que significa que deben tenerse en cuenta los derechos adquiridos y la conexión de la relación jurídica con el Estado requerido (la llamada Inlandsbeziehung). Por lo tanto, dicho de forma sencilla, la autoridad que decida sobre el exequátur debe ser aún más reservada al aplicar la excepción de orden público que al decidir sobre la aplicación de una ley extranjera.

Los temores sobre el posible uso arbitrario de esta norma jurídica surgen en relación con cualquier plan de reforma de las normas sobre el reconocimiento y la ejecu-

65 Andrae speaks of 'exclusive grounds for refusal (ausschließliche Anerkennungsversagungsgründe)': M. Andrae, above n. 23, p. 402.

66 En la sentencia de 2019 en el asunto n. C-386/17, Stefano Liberato contra Luminita Luisa Grigorescu, ECLI:EU:C:2019:24, relativa a la interpretación de una norma similar del Reglamento Bruselas I y del Reglamento II bis, el TJUE decidió que esta prohibición se extiende también a la norma de litispendencia, es decir, que la violación de esta norma por el tribunal de origen de la resolución no puede constituir un motivo para denegar el reconocimiento de una resolución sobre la base de la defensa del orden público.

67 Para más información sobre las partes “europeas” de la política pública nacional, véase J. Kramberger Škerl, “European public policy (with an emphasis on exequatur proceedings)' (2011) 3 Journal of private international law, 461-490. 
ción de las resoluciones judiciales extranjeras. Sin embargo, estos temores han resultado infundados, ya que está ampliamente aceptado en la doctrina y la jurisprudencia que la defensa del orden público debe utilizarse como herramienta de "último recurso". Debe interpretarse estrictamente y sólo sancionar las soluciones verdaderamente inaceptables en el contenido de la decisión extranjera (el llamado "orden público sustancial"), o bien en los procedimientos que conducen a la emisión de dichas decisiones (el llamado "orden público procesal"). La parte procesal del control del orden público fue incluida expresamente por el TJUE en su famosa sentencia Krombach del año $2000,{ }^{68}$ después de un tiempo de especulaciones sobre si el orden público del Convenio de Bruselas debía interpretarse de forma estricta, de modo que se excluyera cualquier cuestión procesal, siendo la única cuestión de este tipo regulada por separado como el motivo de denegación número dos, es decir, la falta de notificación del documento introductorio en caso de sentencia en rebeldía (igual que en los Reglamentos gemelos).

La cuestión de si el alcance de la defensa del orden público es enteramente interpuesta por los Estados miembros (porque el artículo pertinente de los reglamentos menciona expresamente "el orden público en los Estados miembros") o bien debe ser interpretada autónomamente por el TJUE (porque es una noción de la legislación de la UE, que debe aplicarse uniformemente en toda la UE), se resuelve desde el caso Maxicar del TJUE de $2000 .{ }^{69}$ De forma muy consciente, el TJUE adoptó una solución de compromiso en el sentido de que la interpretación queda en manos de las autoridades nacionales de los Estados miembros, pero el TJUE ejerce el control de la aceptabilidad de dicha interpretación en la UE. En pocas palabras, el TJUE controla si los Estados miembros han ido demasiado lejos en sus interpretaciones, ya sea porque no encontraron una contradicción con su política pública cuando debían hacerlo, o bien porque su interpretación fue demasiado amplia y dio lugar a una restricción inaceptable de la libre circulación de sentencias.

Al igual que otros reglamentos de la UE anteriores, los Reglamentos gemelos contienen, en el artículo 40, una prohibición de revisión de una decisión de otro Estado miembro en cuanto al fondo. Dicha revisión no debe realizarse "bajo ninguna circunstancia". Es importante explicar esta prohibición a la luz del control del orden público, con el fin de garantizar la plena eficacia de ambas disposiciones. En resumen, la prohibición de revisión significa que la autoridad del Estado miembro de ejecución, competente para examinar la solicitud de exequátur, no debe desempeñar el papel de un tribunal de instancia superior al tribunal que dictó la sentencia. El control previsto en el Reglamento es un ejemplo de "control limitado" de una sentencia extranjera (contrôle limité) y no del "control total" (revision au fond). Por lo tanto, el control realizado para aceptar los efectos de la sentencia extranjera es un control especialmente diseñado con un propósito específico, no destinado a "confirmar" o "reparar" la sentencia extranjera; su objetivo es establecer si la sentencia extranjera puede producir efectos en el ordenamiento jurídico nacional, sin dañar su coherencia y sus valores fundamentales. Por lo tanto, el control no debe centrarse en la cuestión de si el tribunal de origen estableció correctamente los hechos del caso, en si aplicó correctamente el derecho procesal y sustancial aplicable, y menos aún en la cuestión de si se habría alcanzado el mismo resultado, si el caso se adujera en el estado de ejecución. El

68 Asunto C-7/98, Dieter Krombach contra André Bamberski, ECLI:EU:C:2000:164.

69 Asunto n. C-38/98, Régie nationale des usines Renault SA contra Maxicar SpA y Orazio Formento, ECLI:EU:C:2000:225. 
control debe centrarse en la existencia de la posible contrariedad de, en primer lugar, el resultado jurídico sustancial que contiene la sentencia y, en segundo lugar, del procedimiento que condujo a la emisión de la sentencia, con el orden público del Estado requerido.

Sin embargo, no hay que confundir la finalidad del control que se ejerce con el método para realizarlo. Para examinar la conformidad de la sentencia con el orden público, la autoridad competente no tendrá, en la mayoría de los casos, más remedio que examinar el fondo de la sentencia. Es sobre todo mediante la lectura atenta de toda la sentencia, es decir, especialmente la explicación de los motivos de la decisión adoptada, como se podrá establecer si se han truncado los derechos de defensa o si se condena al demandado a pagar una determinada suma de dinero por un motivo que quizá resulte chocante para el estado de la ejecución. ${ }^{70}$

Además, la redacción de los Reglamentos gemelos de que la contrariedad al orden público debe ser "manifiesta", no debe inducirnos a pensar que la autoridad que decide sobre el exequátur no está autorizada a examinar a fondo la sentencia. El carácter manifiesto de la violación del orden público debe estar en la intensidad de la colisión con los valores fundamentales del estado de ejecución, y no (necesariamente) en el hecho de que sea evidente a primera vista de la sentencia.

\subsection{La falta de notificación del documento introductorio en el procedimiento}

Podría decirse que la garantía procesal más importante en los procedimientos civiles es la debida notificación del documento introductorio del procedimiento. Es un punto crucial en cualquier procedimiento judicial, que establece una relación tripartita entre las partes y el tribunal. La debida notificación del documento introductorio es un requisito previo para el derecho efectivo a ser oído (es decir, el principio de contradicción) y, además, para la igualdad de armas de ambas partes, esenciales en el derecho a un juicio justo del artículo 6 del Convenio Europeo de Derechos Humanos y Libertades Fundamentales (el $\mathrm{CEDH})$, así como de las constituciones nacionales y la legislación procesal de los Estados miembros de la UE.

Los Reglamentos gemelos establecen que el reconocimiento y la ejecución pueden ser denegados, cuando la resolución "se haya dictado en rebeldía, si no se ha notificado al demandado el escrito de interposición del recurso o un documento equivalente con la suficiente antelación y de forma que le permita organizar su defensa, a menos que el demandado no haya iniciado el procedimiento de impugnación de la resolución cuando le fue posible hacerlo".

Con la ya mencionada sentencia Krombach de 2000, el TJUE resolvió definitivamente el dilema de si la falta de notificación debida del documento introductorio en el procedimiento era la única cuestión procesal que podía dar lugar a la denegación del reconocimiento y la ejecución de una sentencia en virtud del Convenio de Bruselas. De

70 Por ejemplo, una sentencia que obliga a una parte a pagar una determinada suma de dinero a la otra parte es un caso cotidiano en todos los Estados miembros y, por lo tanto, nada especial o chocante. Sin embargo, el motivo por el que se debe realizar este pago puede ser inaceptable y contrario al orden público del Estado miembro de ejecución. Por lo tanto, es importante que el tribunal del Estado miembro de ejecución examine también los motivos de la sentencia y que deniegue la ejecución si establece que, por ejemplo, el pago se debe a la aplicación de una norma discriminatoria, que atribuye una parte mayor de los antiguos bienes comunes a uno de los cónyuges sólo sobre la base de, por ejemplo, su sexo. 
acuerdo con esta sentencia, otras violaciones de las garantías procesales fundamentales (como, por ejemplo, la violación del derecho a ser oído durante el procedimiento, tras una notificación correcta del documento introductorio) pueden ser sancionadas a través de la excepción de orden público. Sin duda, esta interpretación debe extenderse a todos los reglamentos de la UE con la misma o similar redacción de los motivos de denegación y, por tanto, también a los Reglamentos gemelos. Puede sorprender el hecho de que los reglamentos de la UE adoptados en este ámbito tras la emisión de la sentencia Krombach sigan conteniendo una mención separada a la falta de notificación del documento de presentación, a pesar de formar parte del orden público procesal que ahora abarca la excepción de orden público. Si bien esta mención separada ya no puede interpretarse como se ha descrito anteriormente, puede verse ahora como un énfasis de la importancia de este elemento de orden público procesal, con precisiones bienvenidas sobre la posibilidad de invocarlo en el procedimiento de exequátur, que no se deja así a la interpretación de los tribunales nacionales. Si la interpretación del contenido del orden público queda en gran medida en la esfera de los Estados miembros, el texto del segundo motivo de denegación no contiene ninguna mención a los Estados miembros y la interpretación autónoma podría ser asumida plenamente por el TJUE.

La jurisprudencia del TJUE sobre la interpretación del mismo motivo de denegación del Reglamento Bruselas I bis es abundante y debería ser seguida por los tribunales cuando interpreten los Reglamentos gemelos. Así, los criterios, según los cuales el documento introductorio debe ser notificado al demandado con tiempo suficiente y de forma que le permita preparar su defensa, pueden cumplirse, aunque la notificación no haya sido regular según las normas procesales nacionales del Estado miembro de origen. ${ }^{71}$ Por ejemplo, aunque las normas procesales exijan que el demandado sea notificado personalmente, es decir, que se necesite su firma en el certificado de notificación, pero la notificación se haya hecho en realidad al compañero de piso del demandado, esto no será un problema según el Reglamento, si se demuestra que el demandado recibió, de hecho, el documento introductorio con suficiente información y tuvo tiempo suficiente para preparar su defensa.

En el Reglamento se hace un énfasis muy importante en cuanto a los límites de la invocación de dicho motivo de denegación. En concreto, si el demandado tuvo la oportunidad de invocar la falta de notificación adecuada en el Estado miembro de origen, ya no podrá recurrir al Estado miembro de reconocimiento para subsanar dicha violación procesal. Esto está en consonancia con el principio general de que los Estados deben tener la posibilidad de reparar sus errores antes de que entre en acción un mecanismo internacional, pero también con el principio de un proceso civil eficaz y expeditivo, en el que las partes deben proteger activamente sus derechos durante todo el proceso (y no con carácter retroactivo, si el resultado del proceso les es desfavorable). El tribunal debe garantizar que las partes tengan la posibilidad de participar en el procedimiento y defender sus derechos, pero las partes deben asumir las consecuencias si no lo hacen, aunque puedan hacerlo. Por eso es tan importante aclarar si la postura pasiva de una parte fue realmente su elección, o bien fue consecuencia del hecho de que la parte no sabía que se había iniciado el procedimiento o no tuvo tiempo suficiente para responder adecuadamente. En la sentencia $A S M L$, el TJUE precisó además que sólo se considera que el demandado tuvo

71 Caso n. C-283/05, ASML Netherlands BV contra Semiconductor Industry Services GmbH (SEMIS), ECLI:EU:C:2006:787. 
la oportunidad de oponerse a la falta de notificación de la demanda, si posteriormente no sólo tuvo conocimiento de la existencia de la sentencia en rebeldía, sino que también conoció los fundamentos de dicha sentencia. Esto está en consonancia con otro principio procesal según el cual las sentencias han de ser motivadas, lo que permite a las partes presentar un recurso argumentado y a los tribunales de apelación llevar a cabo una revisión.

Dicho esto, es importante reiterar que la notificación debida se interpreta de forma autónoma, lo que implica también la posibilidad de que el Estado miembro de ejecución (o el TJUE, si se le pide) establezca que una notificación efectuada con respecto a las normas del Estado miembro de origen, no se hizo de tal forma y con tiempo suficiente para que el demandado pudiera preparar su defensa. De este modo, el demandado puede denunciar, en un procedimiento de exequátur, la insuficiencia de la notificación del documento introductorio que no pudo invocar en el Estado miembro de origen.

\subsection{Motivos de denegación del reconocimiento de las resoluciones}

El tercer motivo de denegación de reconocimiento y ejecución de los Reglamentos es la irreconciliabilidad o incompatibilidad de las resoluciones. De nuevo, la interpretación de la misma norma en otros Reglamentos de la UE puede servir de orientación. Se presentan dos situaciones. En primer lugar, que la resolución de otro Estado miembro contradiga una resolución dictada en el Estado miembro de reconocimiento o ejecución, y en segundo lugar, que la resolución sea incompatible con una resolución de otro Estado miembro (es decir, que no sea el Estado donde se solicita el reconocimiento o la ejecución).

En el caso de una sentencia interna contradictoria, ésta debe haber sido dictada en un procedimiento entre las mismas partes, pero no necesariamente sobre el mismo objeto. Andrae pone el ejemplo de una sentencia nacional sobre el estatuto personal, que es incompatible con una sentencia de relaciones patrimoniales de otro Estado miembro basada en un estatuto personal diferente de las partes. ${ }^{72}$ Asimismo, los Reglamentos no exigen que la resolución nacional se emita antes de la emisión de la resolución de otro Estado miembro. Esto es algo contradictorio con el reconocimiento ipso iure de las resoluciones en todos los Estados miembros participantes, donde en principio las resoluciones surten efectos en todos esos Estados al mismo tiempo. Por otra parte, la parte interesada podría haber invocado una sentencia extranjera anterior en el procedimiento nacional (el tribunal la habría reconocido incidentalmente). Si esto no se hizo a tiempo, el Reglamento no impone a los Estados miembros la prevalencia de una sentencia extranjera sobre una sentencia nacional firme.

En el caso de una resolución incompatible de otro Estado miembro o de un tercer Estado, ésta debe haber sido dictada con anterioridad a la resolución cuyo reconocimiento se solicita y entre las mismas partes, y debe implicar la misma causa de acción, así como cumplir las condiciones para el reconocimiento en el Estado requerido. La prevalencia de una sentencia de otros Estados requiere, por tanto, el cumplimiento de condiciones más estrictas que las establecidas para las sentencias nacionales. En primer lugar, dicha sentencia debe ser anterior a la sentencia cuyo reconocimiento o ejecución se solicita. En segundo lugar, dicha sentencia debe referirse no sólo a las mismas partes, sino también a la misma "causa de la acción". Y en tercer lugar, dicha resolución debe poder ser

72 Cf. M. Andrae, above n. 23, p. 402. 
reconocida en el Estado miembro requerido. Por lo tanto, si dicha resolución se dicta en otro Estado miembro participante, el reconocimiento es automático y no existe ninguna condición. Por otro lado, si la resolución se origina en uno de los Estados miembros de la UE no participantes o en un tercer Estado, deben aplicarse las normas nacionales sobre el reconocimiento de las resoluciones extranjeras.

\subsection{Orientaciones adicionales sobre el examen de motivos de denegación}

Los Reglamentos destacan en primer lugar que los motivos de denegación deben examinarse respetando los derechos fundamentales. Esto es probablemente evidente, pero no hay nada de malo en esta disposición, que podría impedir una interpretación que se aparte de las normas de derechos humanos comúnmente aceptadas, como las contenidas en la Carta de Derechos Fundamentales de la UE, ${ }^{73}$ así como en el CEDH, del que todos los Estados miembros de la UE son parte. Esto puede ser especialmente importante en la interpretación de la excepción de orden público, como se demostró de forma más destacada en el asunto Krombach del TJUE, en el que el Tribunal incluyó en el ámbito de la defensa del orden público también la protección del orden público procesal, que, en aquel momento, no era una postura doctrinal unánime, pero que, sin embargo, estaba en consonancia con el artículo 6 del CEDH.

A diferencia del Reglamento de Bruselas I bis, ${ }^{74}$ los Reglamentos gemelos no prevén ningún control de la competencia del tribunal de origen de la resolución. ${ }^{75}$ Esto fomenta aún más la libre circulación de las sentencias, ya que se suprime un posible motivo de denegación, pero puede parecer sorprendente, ya que el sistema muy liberal de reconocimiento y ejecución estaba, en la normativa de la UE, tradicionalmente vinculado al respeto de las disposiciones sobre jurisdicción de la misma normativa, y al menos el incumplimiento de las normas jurisdiccionales más importantes podía dar lugar a la denegación del reconocimiento y la ejecución en el extranjero. No obstante, apoyamos esta decisión legislativa, ya que, en principio, no hay partes más débiles que deban ser protegidas, y la jurisdicción a menudo se une a otros procedimientos relacionados, como los procedimientos de divorcio y los relativos a la sucesión. En estos casos, la mayoría de las veces, es en interés de las partes prevalecer la acumulación, y el interés público es posiblemente menos pronunciado que, por ejemplo, en las jurisdicciones exclusivas en virtud del artículo 24 del Reglamento Bruselas I bis.

\section{OBSERVACIONES FINALES}

Los Reglamentos gemelos establecen las normas sobre "reconocimiento, fuerza ejecutiva y ejecución de las resoluciones" en el capítulo IV. El reconocimiento se produce ipso iure, mientras que la ejecución sólo es posible tras la obtención del otorgamiento de la ejecución (exequatur) en un procedimiento especial llevado a cabo en el Estado miembro de ejecución. Estas normas son en gran medida idénticas y siguen el sistema bien cono-

73 A este respecto, Andrae subraya el respeto de la prohibición de discriminación: M. Andrae, above n. 23 , p. 402.

74 Article 45(1) e) of the Brussels I bis Regulation.

75 Véase, por ejemplo, Sentencia del TJUE en el asunto Liberato, arriba n. 73. 
cido por los juristas europeos del Reglamento Bruselas I, que ya sirvió de matriz para las normas de reconocimiento y ejecución de las resoluciones en el Reglamento de sucesiones, así como en el Reglamento de alimentos, cuando se solicita la ejecución de una resolución dictada en un Estado miembro no vinculado por el Protocolo de La Haya de 2007 (capítulo IV, sección 2). Paul Lagarde escribió: "Los Reglamentos sobre regímenes patrimoniales siguen una especie de derecho común europeo sobre el reconocimiento y la ejecución de resoluciones y documentos públicos". ${ }^{76}$ Asimismo, el considerando 55 del Reglamento sobre los efectos patrimoniales de las uniones registradas (y el considerando 56 del Reglamento sobre el régimen económico matrimonial) hace hincapié en esta conexión: "A la luz de su objetivo general, que es el reconocimiento mutuo de las resoluciones dictadas en los Estados miembros en materia de efectos patrimoniales de las uniones registradas, el presente Reglamento debe establecer normas relativas al reconocimiento, la fuerza ejecutiva y la ejecución de las resoluciones similares a las de otros instrumentos de la Unión en el ámbito de la cooperación judicial en materia civil."

La ejecución (real), tras la declaración de ejecutoriedad, se llevará a cabo siempre con arreglo a las normas procesales nacionales del Estado miembro de ejecución. En principio, los reglamentos de la UE no interfieren con estas normas. Regulan la fase de "transición" de la sentencia extranjera al sistema jurídico nacional, es decir, la fase previa al procedimiento de ejecución (real), que será la misma que para las sentencias nacionales. Al decidir sobre la solicitud de ejecución (real), la autoridad de ejecución ya no verificará la existencia de los motivos de denegación del Reglamento: la decisión sobre el exequátur, emitida en el procedimiento de exequátur (¡necesariamente!) ${ }^{77}$ separado, es vinculante para todas las autoridades nacionales. Se podría argumentar que, para evitar la confusión, habría sido más claro que los reglamentos de la UE en el ámbito del "reconocimiento y la ejecución" sólo hablaran de la "ejecutoriedad" de las decisiones de otros Estados miembros y no de la "ejecución", con la excepción de los casos en que las normas se refieren a la ejecución (real), por ejemplo, a una posible suspensión de la misma.

Si miramos hacia el futuro, los objetivos generales de la UE permiten predecir con relativa seguridad que, con el tiempo, también las sentencias en las relaciones patrimoniales de las parejas no sólo se reconocerán automáticamente, sino que también serán automáticamente ejecutables en otros Estados miembros. El tiempo mostrará si el primer paso de la evolución será atraer a más Estados miembros, y posiblemente a todos, para que se unan a la cooperación reforzada en este ámbito, o si los Estados miembros que actualmente participan continuarán su camino hacia un sistema de circulación de sentencias aún más liberal. Dado que el sistema actualmente previsto en los Reglamentos gemelos es ya muy aceptable en cuanto al fondo y está muy bien probado en la práctica, el autor preferiría la primera opción, es decir, intentar que se adhieran más Estados miembros. Para ello, es importante reunir y demostrar las buenas prácticas y los "casos de éxito", con el fin de persuadir a los que aún dudan de la eficacia y la relativa sencillez del sistema establecido por el Reglamento, así como para destacar el respeto que el Reglamento muestra hacia las nociones nacionales de derecho de familia de cada Estado miembro participante.

76 P. Lagarde in U. Bergquist et al., above n. 33, p. 12.

77 A diferencia de algunas legislaciones nacionales (por ejemplo, la de Eslovenia), la normativa no contempla el auto de ejecución en el marco de un procedimiento de ejecución. 